\title{
Improving Service Quality in Public Transportation in Brazil: How Bus Companies are Simplifying Quality Management Systems and Strategic Planning to Increase Service Level?
}

\author{
Helcio Raymundo, João G. M. Reis, Pedro L. O. Costa Neto, \\ Oduvaldo Vendrametto, Emerson R. Abraham, Marcos O. Morais, \\ Carla C. Parizi, Sivanilza T. Machado, Helton R. O. Silva, and \\ Antônio S. Brejão \\ Postgraduate Studies Program in Production Engineering \\ Dr. Bacelar 1212, 04026002 São Paulo, São Paulo, Brazil \\ \{helcioru, politeleia, oduvaldov, prof .sergiobrejao\}@uol.com.br \\ \{betomendesreis, kaa_ell\}@hotmail.com \\ \{sivateixeira, emerson_abraham\}@yahoo.com.br \\ marcostecnologia@ig.com.br \\ ccapraraparizi@gmail.com
}

\begin{abstract}
Improving the service quality in public transportation is essential for convinced users to abandon the use of private cars. However, to improve service quality, companies need to adopt a quality management system and strategic planning which is not an easy task. This paper presents a way of simplifying a Quality Management System (QMS) and developing a Simple Strategic Planning (SSP) to be adopted for bus transportation companies. A methodology is developed and showed in this paper, together with a case study that illustrate the system. A Brazilian Bus Company applied the methodology and reached an improvement of their service levels with low costs.
\end{abstract}

Keywords: Bus Companies; Public Transportation; Strategic Planning; Quality Management Systems.

\section{Introduction}

Improving service quality is a key-factor to persuade drivers to change the private car for the public transportation systems [1]. Reducing private transport use and increasing public transportation is not an easy task, because it is necessary to change the behavior of potential users [2]. Moreover, the advantages of car use consist in allowing a door-to-door transportation without travel on foot and sharing space with others passengers. Therefore, the biggest challenge for public transportation companies is providing high service quality to attract passengers, while trying to cut their costs [3]. 
A way of starting to change this situation involves the understanding of these companies in adopting a management model with parameters to improve service level. Thus, these management models need to answer some questions: (i) How the information of importance is collected and interpreted? (ii) How the strategic guidelines of the company become Action Plans? (iii) How the Action Plans are applied in practice? and (iv) How the effectiveness of the Action Plans is measured in relation to the strategic guidelines?

In Brazil, public transportation is a pool that involves public and private companies. Generally, rail services operate for public companies and bus services for private companies. The bus companies often struggle to produce enough knowledge generated by selecting and reviewing the information, which ultimately reduces confidence in strategic planning [4]. This situation occurs because they do not know how clearly the information is interconnected, and what the highest priority in each process is? This causes a loss of time, because it generates an analysis of information that is sometimes disconnected from the strategic actions.

Furthermore, bus companies believed that Quality Management Systems QMS are costly, and increase internal bureaucracy. At the same time, strategic planning is seen as too expensive and a complex process, usually requiring external consultants [4]. In addition, they believe that strategic planning produces guidelines that are oftentimes not connected with the reality of enterprises [4].

In an environment of crisis and with the threat of unsatisfactory profitability, it is recommendable that the bus companies have a solid and efficient decisionmaking process. However, for the majority of the time, it is difficult for them to recover losses as a result of ill-conceived action strategies or action plans badly implemented or partially implemented.

The service level of bus companies increases considerably when they begin to understand, accept and apply concepts of QMS and strategic planning [4] and [5]. The first element is the foundation, because, among other things, it focuses on customers; and the second element is the driver for the future, as it streamlines the companies' actions. However, in both cases, the base is always the source, the collection, the organization and the processing of the information to feed the relevant indicators that adequately measure the quality and efficiency of the processes that produce the actions of the enterprises.

Previous researches focused on analyzing service quality of public transportation studying user behavior, government regulations and polices [1], [2], [3], [6] and [7]. Unfortunately, none of these studies are concentrated in understanding that the problem of service quality is linked with inefficiency of model management of transportation companies.

The purpose of this paper is to study how a Simple Strategic Planning (SSP) and a simplifying QMS can contribute for increased service level and quality in bus companies operating in Brazil. 


\section{Methodology}

This article presents a methodology to simplify a QMS and develop SSP to apply in management of bus companies. The purpose of this methodology is to allow that companies reach better service levels improving their management systems. To show the utility of this methodology, our study was divided based on the following steps:

- The first step: a study on the importance of information to increase service levels and transportation systems is conducted. Its purpose is understand the scenario in which companies need to improve the service quality;

- The second one: The simplifying QMS and SSP are developing considering the studies of [4], [5], [8], [9], [10], [11], [12], and [13].

- Finally: one case study is performed to illustrate the methodology and its results.

\section{Information}

\subsection{Demand}

The demand information, generally, is not freely available, because the decisionmakers of companies, normally the owners themselves, usually establish specific ways to deal with this kind of information. Nevertheless, the information of demand is a fundamental element to establish priorities, particularly related to the market [5].

Some indicators of demand that can be used in some levels of the organization to increase service level and bring satisfactory results. The most common indicators are IPK - Index of Passengers per Kilometer and PDV - Total Passengers per Day and per Vehicle. It should also be noted that the simple analysis of these two indicators may generate decisions that influence the profitability of bus companies. For example, if a bus line shows PDV lower than another one, the first one may be more profitable [14].

\subsection{Customer Satisfaction}

Customer satisfaction is an indicator that has been used by some bus companies in Brazil. However, this occurs only due to the worsening of the illegal transportation phenomenon. This phenomenon consists of transportation services, mainly by one vehicle, a van or a minibus, driven by its own owner. This kind of transportation operates without proper agency permits or certificates.

Illegal operators often do not have proper insurance; they do not conduct background checks for employees, also illegal, or perform regular safety inspections on their vehicles. However, they were very popular, especially in the 1990s and 2000s, because they were faster and more comfortable than regular buses in many Brazilian cities [9]. This reality obligates bus companies to improve their operations, buying new buses and training bus drivers. 


\subsection{Operational}

Operational information can be considered the most complex and less trustworthy in bus companies. This kind of information is generated in various sectors, from several sources and is usually shown masked to avoid exposing the shortcomings or weaknesses of the sector responsible for its gathering [10].

This kind of information is based on key performance indicators - KPI. To develop a strategic planning three of them need to be considered [8]:

- Compliance Factor (in relation to what was planned): It measures how effectively the planning was fulfilled, because the strict use of a set of resources (no more, no less) was planned and therefore its use should be exactly as planned. Otherwise, there is evidence of the occurrence of wastage;

- Mean Kilometer Between Failure MKBF: It measures the efficiency of preventive maintenance of the buses and how much the potential failures can jeopardize the Compliance Factor, thus generating customer dissatisfaction, and damaging the image of the company; and

- Complaint Index (by kilometer): It shows the extent to which the operation of the service is meeting customer expectations. This indicator should be analyzed by subgroups, such as crew, offer, comfort etc., enabling better understanding of each of the registered complaints.

\subsection{Market}

Market information is usually difficult to be generated and managed as it represents competitive information. Therefore, it is considered highly confidential. The reason to have good market information is justified to understand the company's position in respect to your competitors [15]. Many companies cannot always determine who their real competitors are, making it difficult to establish properly what their weaknesses and threats are.

\section{Simplifying a Quality Management System}

A management system is the interconnection of components to achieve a specific objective more effectively in an organization. These components include the organization itself, resources and processes. Therefore, people, equipment and knowledge, in a certain cultural environment, are part of the system as well as the documented policies and practices [11].

Quality Management System, according to the ISO 9000 standard [11], with a focus on customer satisfaction, is described as how to introduce and use quality management in an organization. The ISO standard is based on a number of quality management principles, including a strong customer focus, the motivation and implication of Top Management, the process approach and continual improvement.

Hence, under these conditions, it is crucial for the organizations to understand the customers requirements and to use them to develop business processes that deliver an acceptable level of services. 
Therefore, these customer satisfaction processes must be monitored and measured to ensure they will deliver the results the customers demand. This is called a process control.

In order to simplify the QMS it is recommendable that organizations adopt and pay attention to the results of three key elements [13]:

- Customer Satisfaction: It means understanding what customer satisfaction is and making sure that every employee understands how to deliver it;

- Corrective Action: It means identification of the sectors in the company that are not satisfying the customer's needs and taking corrective action to make sure that this never happens again; and

- Preventive Action: It means identifying sectors within the company that are at risk of not satisfying the customer's needs, understanding the marketplace trends, capabilities and threats to satisfying the customer, and then taking preventive action to make sure that this never happens in the first place.

\section{Developing a Synthetic Model for Strategic Planning}

The changes of paradigms and values have influenced the management of organizations, and have forced the bus companies to promote substantial changes to meet the demands of the market. Hence, it was essential for these companies to adopt a strategic planning and to take into account the needs of the market, technological innovations, new customer segmentation and application of up-to-date administration techniques, simplified and effective.

There is no one perfect strategic planning model. Each organization ends up developing its own nature and model of strategic planning, often by selecting a model and modifying it as they go along in developing their own planning process [13].

In our study we develop a Simple Strategic Planning to be used for bus companies. The SSP is divided in some steps:

- The first step: is to establish comparative parameters with the competititors;

- Second: is to analyze the current situation of the bus company;

- Third: is to determine where the company wants to be and where it wants to go;

- Fourth: is to define or to realign the companys mission;

- Fifth: consists in establishing the main goal of the company taking into consideration: the weaknesses and threats and the needs of the stakeholders. The main goal must be deployed in action plans for each sector of the company and sectorial goals must be established for each sector and each process;

- Sixth: is to develop parameters and indicators to monitor effectively the main goal and sectorial goals. The scheme can be seen in Figure 1. 
- Seventh: is to ensure that the information related to the main goal and sectorial goals is trustworthy; and finally

- Eigth: it is necessary to apply continually the PDCA cycle (Plan, Do, Check, Action), as represented in Figure 2.

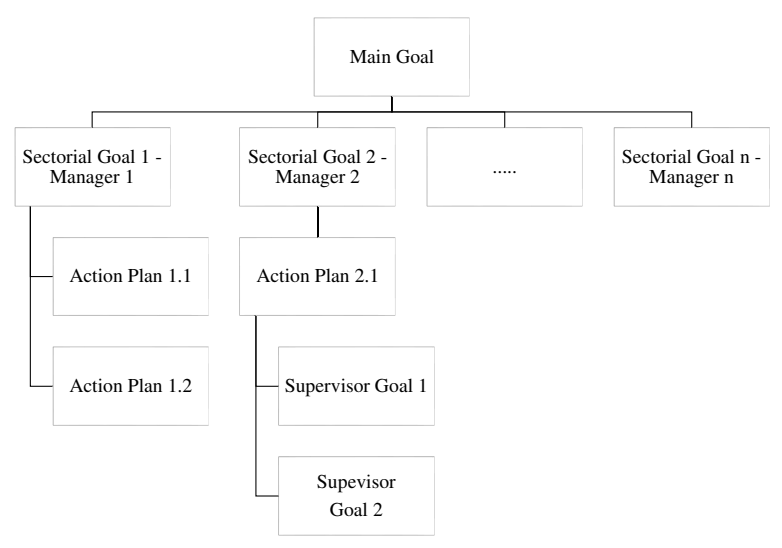

Fig. 1. Deployment of Main Goal in Sectorial Goals

\section{Case Study}

The Bus Company adopted in this case study was partly professionalized according to its size and fairly well-organized. This company was trying to implement a QMS, when they started experiencing some issues. The implementation of the QMS did not take off because, according to the Board of Directors, there would be no effective senior management commitment. Moreover, according to the senior manager, the quality could represent unbearable additional costs.

The Diagnosis [4] showed that both were part of the reason, but it went further. It was proved that the strategic planning was almost inexpressive. The Suggested Solution [4] was simplifying QMS and convinced the Board of Directors to obtain an ISO 9001:2008 certification. Thus, a SSP was adopted to help bus company to manage its service level.

It should be said that an ISO 9001: 2008 certification in a bus company has one main conceptual difficulty in interpreting the requirements of the standards, originally designed to be applied to manufacturers and not to services. In practice, and in fact, the main difficulty is to transform the existing informal procedures into formal procedures and implement them.

Once the SSP was adopted, it clearly demonstrated the strategic importance of the achievement of the ISO 9001:2008 certification, not the opposite, as was 


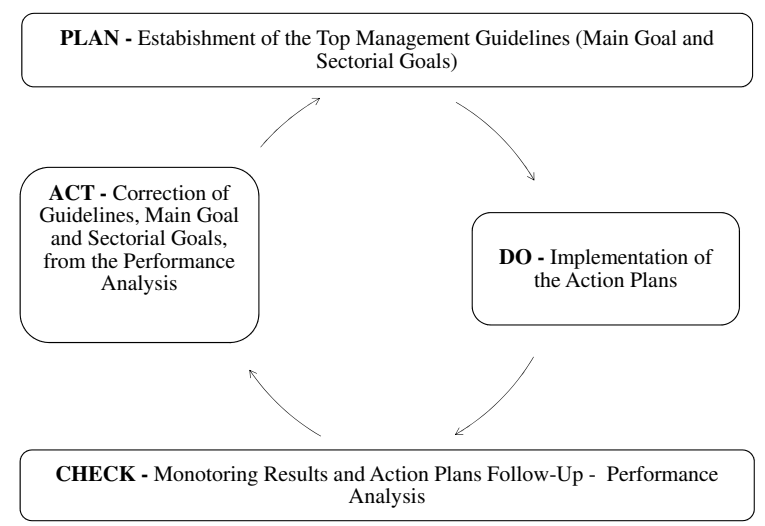

Fig. 2. PDCA Cycle

being disclosed in the company previously. The results were that the certification activities were quickly completed in just nine months. The company prepared $100 \%$ of its procedures, set most of the informal procedures, prepared and applied internal audit, pre-audit and certification audit.

The estimated impact on the costs of hiring an accredited certification authority and a consultant, training and the time consumed by the managers and other employees involved, will be about $1 \%$ of total annual revenue, spent in 12 months. The costs are being offset by productivity improvement, a new structure and a competitive company image.

Completing the process of improving management, the Bus Company has simplified its QMS and has achieved growing results of profitability, superior customer service level and image enhancement.

\section{Conclusions and Outlook}

The paper allows the conclusion that the adoption of a simplified QMS linked with a Simple Strategic Planning and supported by the information may define or redirect the bus companies strategies. A case study of a Brazilian bus company showed that it increased service levels and consumer satisfaction adopting a SSP and a simplifying QMS, using the ISO 9001:2008. The costs represented 1\% of annual company revenue.

The improvement in service levels and quality in public transportation is very important to increase the numbers of passengers in the system and reduce the use of private cars that generates intensive traffic in peak and non-peak hours. The solution for emission reduction of $\mathrm{CO}_{2}$ in the atmosphere, the efficiency of land use and the reduction of travel time is public transportation. Hence, this study contributed to recommend ways to improve quality of services and 
to increase the use of public transportation in the cities for bus companies and governments.

\section{References}

1. Liou, J.J., Hsu, C.C., Chen, Y.S.: Improving transportation service quality based on information fusion. Transportation Research Part A: Policy and Practice 67, 225-239 (Sep 2014)

2. Lai, W.T., Chen, C.F.: Behavioral intentions of public transit passengers: the roles of service quality, perceived value, satisfaction and involvement. Transport Policy 18(2), 318-325 (Mar 2011)

3. Maha, A., Bobalca, C., Tugulea, O.: Strategies for the Improvements in the Quality and Efficiency of Public Transportation. Procedia Economics and Finance 15, 877885 (2014)

4. Raymundo, H., Vendrametto, O., Reis, J.G.M.d.: Knowledge Management in Public Transportation: Experiences in Brazilian Bus Companies. In: Grabot, B., Vallespir, B., Gomes, S., Bouras, A., Kiritsis, D. (eds.) Advances in Production Management Systems. Innovative and Knowledge-Based Production Management in a Global-Local World, pp. 603-610. No. 439 in IFIP Advances in Information and Communication Technology, Springer Berlin Heidelberg (Sep 2014)

5. US Department of Commerce: Information Security. Tech. rep., US Department of Commerce (2011), http://www.nist.gov

6. Pestana Barros, C., Peypoch, N.: Productivity changes in Portuguese bus companies. Transport Policy 17(5), 295-302 (Sep 2010)

7. Yeh, C.H., Deng, H., Chang, Y.H.: Fuzzy multicriteria analysis for performance evaluation of bus companies. European Journal of Operational Research 126(3), 459-473 (Nov 2000)

8. Austin, R.D.: Measuring and Managing Performance in Organizations. AddisonWesley (Jul 2013)

9. Cervero, R.: Informal Transport in the Developing World. UN-HABITAT (2000)

10. Dunlop, D., Stewart, W.: Central Area Bus Operational Review. Tech. rep., http: //www.gw.govt.nz

11. ISO: Management system standards (2015), http://www.nist.gov

12. U.S. Small Business Administration: Planning and Goal Setting for Small Business. Tech. rep., U.S. Small Business Administration, USA (2015), https://www.sba. gov

13. Westcott, R.: Simplified Project Management For The Quality Professional: Managing Small And Medium-size Projects. Amer Society for Quality, Milwaukee, Wis (Sep 2004)

14. ANTP: Sistema de Informaes da Mobilidade Urbana (2015), http://www .antp. org.br

15. Tirole, J.: Market Power and Regulation (2014), http://www.nobelprize.org 